\title{
LECCIONES DE LUCA PACIOLI PARA JUAN SÁNCHEZ, MAESTRO MAYOR DEL AYUNTAMIENTO DE SEVILLA
}

\section{LESSONS FROM LUCA PACIOLI FOR JUAN SÁNCHEZ, MASTER BUILDERS OF SEVILLE'S CITY COUNCIL}

\author{
Alfredo J. Morales \\ Universidad de Sevilla. España \\ ORCID: 0000-0001-5986-3124 \\ ajmorales@us.es
}

Se desconoce prácticamente la vida y la actividad profesional de Juan Sánchez, quien fue maestro mayor del Ayuntamiento de Sevilla. Se aportan en el presente texto noticias inéditas extraídas de documentos notariales, destacando las correspondientes a las lecciones de matemáticas, basadas en el libro de fray Luca Pacioli, que contrató en 1550 con el maestro Antón de Molina.

Palabras clave: arquitectura; cantería; matemáticas; ciencia; tratados.

Juan Sanchez's life and career path are barely known, despite the fact he was one of the master builders of Seville's city council. This study provides some unpublished news extracted from notarial deeds. Among them, it is necessary to highlight documents corresponding to mathematics lessons, based on Fray Luca Pacioli’s book, who was hired with the master Antón de Molina in 1550.

Keywords: architecture; masonry; mathematics; science; treatises.

En el ámbito de la arquitectura sevillana del Renacimiento, la figura de Juan Sánchez, quien ocupó el puesto de maestro mayor de las obras del Ayuntamiento entre 1535 y 1560, continúa siendo un misterio. Las escasas noticias conocidas sobre su biografía y producción artística no permiten establecer ni su desarrollo vital, ni su trayectoria profesional. De hecho, sobre dicho maestro se cuenta con la limitada información suministrada por las nóminas de las obras de dicho edificio y con los datos ofrecidos por algunas escrituras notariales. Así, se sabe que junto a Martín de Gainza otorgó un poder para presentar ofertas en la construcción de una muralla en Gibraltar y que edificó la capilla que Baltasar de Almansa tenía en la iglesia

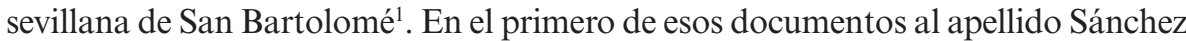
se agrega el "de Caliz", lo que podría indicar su posible origen o vinculación con la

${ }^{1}$ HERNÁNDEZ DÍAZ, José: “Arte y artistas del Renacimiento en Sevilla”, en Documentos para la Historia del Arte en Andalucía. T. VI. Sevilla, 1933, pp. 5 y 58. 
ciudad de Cádiz, dato que no se ha podido corroborar. Por otra parte, le atribuí la traza de la fuente ochavada que existió en la plaza de San Francisco y que fue inaugurada en 1545 para las fiestas que iban a celebrarse por el nacimiento del príncipe don Carlos y que fueron suspendidas por el fallecimiento de su madre, la princesa doña María Manuela de Portugal, mujer del futuro rey Felipe II $^{2}$. A la aludida pobreza de información hay que agregar la existencia de distintas personas con el mismo nombre y apellido, lo que puede llevar a la confusión y a asignar al maestro referencias o datos que no le corresponden. Al respecto ya tuve ocasión de señalar cómo en las propias obras de las Casas Capitulares participó un cantero del mismo nombre, que nada tenía que ver con el maestro mayor ${ }^{3}$. Por otra parte, se tienen noticias de fechas próximas a las antes indicadas de personajes coincidentes en nombre y apellido, pero con distinta profesión ${ }^{4}$.

A ampliar el conocimiento sobre la vida y obra de Juan Sánchez contribuyen dos documentos notariales inéditos que han sido localizados en el Archivo de Protocolos Notariales de Sevilla. El primero corresponde a la venta de un tributo escriturado por el maestro el 27 de febrero de 1559 ante el escribano Cristóbal de la Becerra $^{5}$. Junto al artista aparece su mujer Ana Sánchez, indicándose que eran residentes en la collación de la Magdalena. En ella también vivía Alonso de la Serna a quien el matrimonio, de común acuerdo y sin coacciones, le vendieron el tributo que por 3.750 maravedís anuales les pagaban el ollero Lorenzo Martín y su esposa Francisca de Castañeda, por unas casas y ollería que tenían en el barrio de Triana, en la calle de la Cava, actual Pagés del Corro, que lindaban con casas de Juan de Moya y de la morisca Isabel de Soria. Según la escritura, la mencionada venta tenía vigencia desde el 25 de diciembre de 1558. El citado tributo sobre el inmueble trianero fue vendido por los susodichos y al precio de 100 ducados el 25 de agosto de 1551, recibiendo el matrimonio Sánchez dicha cantidad al contado y en reales de plata el día de la firma de la escritura de venta ${ }^{6}$. Si a causa de la escritura de venta se originase algún pleito, el maestro mayor de las obras del cabildo debería abonar las costas que correspondiesen, así como pagar a Alonso de la Serna los 3.750

2 Véase MORALES, Alfredo J.: "Comodidad y plaza pública según Vitruvio. Tres ejemplos sevillanos", Espacio, Tiempo y Forma, Serie VII, 6, 1993, pp. 199-200.

${ }_{3}$ MORALES, Alfredo J.: La obra renacentista del Ayuntamiento de Sevilla. Sevilla, 1981, p. 41.

${ }^{4}$ Es el caso del pintor Juan Sánchez. Véase SANCHO CORBACHO, Heliodoro: "Arte Sevillano de los Siglos XVI y XVII", en Documentos para la Historia del Arte en Andalucía. T. III, Sevilla, 1931, pp. 5 y 18. Otras noticias sobre este artista en HERNÁNDEZ DÍAZ, José: "Arte Hispalense de los siglos XV y XVI", en Documentos para la Historia del Arte en Andalucía. T. IX. Sevilla, 1937, pp. 16, 17, 20 y 21.

5 AHPS (Archivo Histórico Provincial de Sevilla), sección Protocolos Notariales, leg. 2314, oficio 4, lib. I, ff. 647r-649v.

${ }^{6}$ Según el documento, la correspondiente escritura se firmó ante el escribano público Pedro de Castellanos. Ibidem, f. 647r. 
maravedíes anuales en el caso de que Lorenzo Martín y su mujer no lo hiciesen. En caso de no cumplir lo acordado, Sánchez tendría que satisfacer el doble de lo estipulado, además de hacerse cargo de las costas de los procesos judiciales que se planteasen. En todo ello su mujer se mostraba conforme, indicando que no había presentado ningún juramento contrario al documento y que renunciaba a cualquier privilegio o legislación que pudiera favorecerla, habiéndole otorgado su marido licencia para firmar la escritura. Esto no fue posible, pues Ana Sánchez no sabía hacerlo, no pudiendo tampoco firmarlo el maestro mayor de las obras del cabildo sevillano por padecer "perlesía", es decir, una parálisis muscular, síntoma de la esclerosis múltiple, por lo que en sus nombres refrendaron el documento los escribanos Cristóbal y Gonzalo de la Becerra, además de Alonso de Porras.

Gracias a esta escritura notarial se ha podido saber de la residencia de Juan Sánchez en la collación de la Magdalena, de su condición de casado y de que su esposa no sabía escribir. Así mismo constata que en 1559 seguía siendo maestro mayor de las obras de cantería de la ciudad, informando de que padecía una enfermedad degenerativa que le impedía escribir. Tales noticias vienen a apoyar la hipótesis de su posible abandono por una dolencia del puesto de maestro mayor del Ayuntamiento sevillano en 1560, año en el que Hernán Ruiz el Joven asumiría dicho cargo a partir del mes de abril ${ }^{7}$. Por el momento no ha sido posible confirmar si hasta que se produjo este nombramiento pudo haber colaborado con Sánchez en algunas de las tareas del cargo, tal y como se había sugerido ${ }^{8}$.

El segundo de los documentos que se dan a conocer es el convenio que había establecido nueve años antes con Antón de Molina, "maestro de enseñar mozos a leer y escribir", para que le diera lecciones de álgebra, de acuerdo con el libro de "Frater Lucar", es decir, de fray Luca Pacioli ${ }^{9}$. El documento está firmado el primero de marzo del año de 1550 e indica que el maestro mayor de la obra del Ayuntamiento de Sevilla ya residía en la collación de Santa María Magdalena, mientras que Molina habitaba en la de El Salvador. Más allá de la información sobre la localización de la vivienda de Sánchez, el documento es testimonio del interés del cantero por completar su instrucción adquiriendo conocimientos de matemáticas, concretamente de álgebra, que le permitirían el desarrollo de operaciones aritméticas. Si este dato es ya relevante, mucho más lo es el hecho de basar dicha instrucción en la autoridad de Luca Pacioli, aludiéndose a un libro suyo que debe hacer referencia a su obra Summa de arithmetica, geometría, proportioni e proportionalita, considerado como la primera enciclopedia de matemática pura y aplicada. Este texto dedicado al duque de Urbino y publicado por Paganino Paganini en Venecia en 1494,

7 Véase MORALES, Alfredo J.: La obra renacentista..., op. cit., p. 42; y MORALES, Alfredo J.: Hernán Ruiz el Joven. Madrid, 1996, p. 116.

8 Así lo sugería LÓPEZ MARTÍNEZ, Celestino: El arquitecto Hernán Ruiz en Sevilla. Sevilla, 1949, p. 21.

9 AHPS, leg. 6710, oficio 11, lib. I, ff. 498v-499r. 
tuvo una amplia difusión durante el siglo XVI, siendo precisamente testimonio de ello el documento que aquí se da a conocer. Lo que no puede saberse es cómo llegó a conocimiento de Juan Sánchez la existencia de dicho libro y cómo supo que en sus páginas se concentraba lo principal del saber matemático de la época. Podría argumentarse que fue el maestro Molina quien propondría utilizarlo para llevar a cabo la formación que Sánchez precisaba, habida cuenta su claridad expositiva y minuciosidad, así como la falta de otra publicación de características similares ${ }^{10}$. Sin embargo, el texto del documento notarial sugiere que fue el maestro mayor del Ayuntamiento sevillano quien tenía noticia de la existencia del libro de Pacioli y que fue idea suya tomarlo como fuente al solicitar las lecciones. Al respecto es significativo que en el documento se especifique que Molina se comprometía a enseñarle al maestro de las obras del cabildo "a contar toda el arte mayor así el algebra como todo lo demás al dicho arte tocante, como se contiene en el libro de Frater Lucar". Esto vendría a indicar que Sánchez conocía previamente su contenido. Tal suposición parece venir corroborada por el texto de algunas otras frases que forman parte del documento notarial. Así se indica que Molina no estaba "obligado a vos enseñar la geometría del dicho libro", razón por la que debería devolver a Juan Sánchez cuatro ducados de oro de los ocho que le había entregado como pago por las lecciones. Resulta desconocida la razón por la cual el maestro renunció a aprender dicha materia, correspondiente a la segunda parte del libro de Pacioli. Podría pensarse que considerara que su contribución sería limitada para alguien experto como él en el arte de la estereotomía, técnica que le obligaba a saber de geometría y de proporciones. De su dominio como cantero es testimonio su actuación en las obras del Ayuntamiento sevillano. En este edificio añadió a partir de 1535 el piso bajo del ala del arquillo, más el muro del compás del monasterio de San Francisco lindante con la antigua calle Tintores, actual Joaquín Guichot, así como el arco que el mencionado ámbito tenía en esta zona ${ }^{11}$. También fue suya la construcción de la escalera de acceso a la planta alta, con la hermosa bóveda sobre trompas aveneradas de su segundo tramo, elemento que debió concluirse hacia 1545. Así mismo, fueron obra suya las fachadas del piso alto del sector inicial o núcleo del edificio trazado por Diego de Riaño ${ }^{12}$. Efectivamente en estos sectores del edificio municipal se localizan soluciones en el corte de la piedra a la manera renacentista que prueban su dominio en los procesos geométricos que dieron como resultado los patrones de los diferentes sillares, algunos de complejo diseño y volumetría ${ }^{13}$.

${ }^{10}$ Sobre el libro y sus valores puede consultarse GIUSTI, Enrico y MACCAGNI, Carlo: Luca Pacioli e la matemática del Rinascimento. Florencia, 1994.

${ }^{11}$ Dicho muro y arquillo desaparecieron durante las obras desarrolladas en el edificio durante el siglo XIX. Véase MORALES, Alfredo J.: La obra renacentista..., op. cit., pp. 137-ss.

12 Ibidem, pp. 41-42 y 79-85.

${ }_{13}$ Para el tema de la estereotomía española del quinientos es obligada la consulta de la monografía de PALACIOS, José Carlos: Trazas y cortes de cantería en el Renacimiento español. Madrid, 1990. 
Junto con el rechazo a las lecciones de geometría práctica que integran el último capítulo del libro de Pacioli, parece lógico pensar que las enseñanzas de Molina no incluirían los temas relacionados con los negocios, el comercio, los pesos y medidas y, muy especialmente, contabilidad que corresponden al capítulo noveno de la obra. Es bien sabido que en esas páginas se recoge el sistema de doble contabilidad empleado en sus transacciones por los comerciantes del norte de Italia y que gracias al texto de Pacioli alcanzó una amplia difusión, especialmente entre los comerciantes. Se trata de una temática completamente ajena a la profesión de Sánchez y que evidentemente tiene una limitada utilidad práctica para un hombre dedicado al arte de la construcción, aunque podría hacer uso de algunos de sus principios en negocios particulares o en asuntos relativos a nóminas propias o de los canteros que operaban a su cargo. Al respecto debe señalarse que el documento notarial, que incorpora sobre las firmas la frase "conveniencia de le enseñar el arte mayor de contar", precisa que Molina no debería transmitir a Sánchez "la dicha geometría del dicho libro, sino todo lo demás en él contenidos". Esto podría significar que también se incluyeran lecciones sobre los temas del mencionado capítulo noveno.

Volviendo al documento notarial, es preciso señalar que con anterioridad al momento de su firma debía existir un compromiso previo entre Molina y Sánchez, pues en él se indica que el primero ya había recibido a plena satisfacción y al contado ocho de los doce ducados de oro en los que se habían concertado las lecciones. Tuvo que ser en el tiempo transcurrido entre esa entrega y el momento de ratificar la escritura notarial cuando Sánchez decidió prescindir de las lecciones de geometría, pues en ella se indica que Molina tenía que devolverle al maestro cantero cuatro de los ocho ducados que le había entregado. El documento también señala que las lecciones se desarrollarían a lo largo de tres meses, que empezarían a contar desde el mismo día de la fecha de la firma del documento, lo cual tuvo lugar el primero de marzo. Por consiguiente, a primeros de junio se darían por finalizadas las enseñanzas y Sánchez tendría que abonarle los cuatro ducados estipulados. En el caso de no hacerlo en ese momento estaría obligado a entregarle el doble. Por su parte Molina se comprometía a no interrumpir las lecciones y, si por alguna razón al cumplirse el plazo no se hubiera completado la formación, Sánchez no tendría que pagarle. No obstante, también se precisa que si antes de ese momento se hubiera completado el aprendizaje, Sánchez debería abonar la cantidad acordada. En el caso de que este abandonase las lecciones tendría que pagar a Molina 5.000 maravedíes, más las costas que pudieran originarse en caso de un litigio.

Un aspecto interesante del documento es la cláusula por la que el maestro de obras municipal se comprometía a no transmitir los conocimientos de álgebra aprendidos a ninguna persona, en ningún momento o circunstancia. En caso de no cumplir con este punto, Molina denunciaría la existencia del convenio para reclamar al maestro mayor de las obras del cabildo la compensación que se estimase oportuna. Se trataba sin duda de una garantía para el profesor, pues evitaba una competencia que le restaría oportunidades de encontrar otros alumnos 
y, por consiguiente, de seguir obteniendo beneficios por la transmisión de sus conocimientos sobre álgebra. Con independencia de ello, ambos firmantes se comprometían a cumplir el convenio, incorporando el documento notarial la cláusula habitual de dar poderes a la justicia de cualquier fuero para que pudieran actuar en caso de no hacerlo. Como garantía, ambos firmantes se obligaban con sus bienes habidos y por haber, sin recurrir a ninguna otra persona para cumplir ese cometido, fórmula habitual en otros documentos de características similares.

Del documento hasta aquí descrito y comentado hay algunos aspectos que merecen una reflexión. Está en primer lugar la tardía fecha en la que Juan Sánchez se interesa por aprender matemáticas. Aunque no se sabe su fecha de nacimiento, es evidente que en 1550 era ya una persona con amplia experiencia profesional, como puede comprobarse por su mencionado trabajo en las obras de las Casas Capitulares de Sevilla, primero como aparejador y desde 1535 como maestro mayor de las mismas ${ }^{14}$. A ello hay que sumar las otras obras que en solitario o en compañía de otros maestros acometió. Singular es el caso de las que, junto con el arquitecto de la catedral de Sevilla Martín de Gainza, se ofreció a levantar en Gibraltar y a las que antes se hizo alusión. Se trataba de una obra de fortificación, un muro de variable grosor que iría desde el convento de San Francisco, actual The Convent, la residencia del gobernador británico, hasta "encima del cuchillo de una sierra", un trabajo que podría ampliarse a otras "qualesquier obras de cantería e manpostería que fueren menester de se faser en la dicha ciudad de Gibraltar"15. La fecha de este documento permite poner dichas obras en relación con el ataque berberisco que sufrió la plaza en 1540 y prueba el interés por dotarla de elementos defensivos para evitar o repeler futuros asaltos ${ }^{16}$. El ofrecimiento para ejecutar esa obra implicaba el desarrollo de tareas que superaban a las habituales en la construcción de un edificio, tanto por las técnicas a utilizar en razón de su carácter defensivo, como por las peculiares características del accidentado terreno. Esto parece evidenciar, como se anticipó, una preparación profesional por parte de Juan Sánchez superior a la de un simple maestro cantero. Sorprende, por consiguiente, que en fecha tan avanzada careciera de la formación en matemáticas que le solicitó a Antón de Molina.

Otro asunto a plantear son las razones por las que acudió para aprender álgebra a este "maestro de enseñar mozos a leer y escribir". Teniendo en cuenta el puesto que ocupaba y las relaciones profesionales y sociales que mediante ellas habría logrado establecer, resulta asombroso que recurriera a un maestro

${ }^{14}$ Sobre ellas véase MORALES, Alfredo J.: La obra renacentista..., op. cit., pp. 39-42.

15 HERNÁNDEZ DÍAZ, José: “Arte y artistas...”, op. cit., p. 5.

${ }^{16}$ A dicho ataque hace alusión Kagan al comentar y reproducir los dibujos de Wyngaerde que recogen el estado de la plaza y sus fortificaciones en 1567. Véase KAGAN, Richard L. (dir.): Ciudades del Siglo de Oro. Las Vistas Españolas de Anton Van den Wyngaerde. Madrid, 1986, pp. 286-290. 
de primeras letras. Existía en la ciudad un rico ambiente cultural, del que formaban parte además de humanistas, teólogos, renombrados poetas y destacados artistas, un numeroso grupo de expertos en diferentes disciplinas científicas, entre las que destacaban las ejercitadas por los individuos vinculados a la Casa de la Contratación. Eran las correspondientes al arte de navegar y a la cartografía que venían desarrollándose por dicho organismo desde $1508^{17}$. A uno de los cosmógrafos de dicha institución, habida cuenta de su preparación en materias como la geometría, las matemáticas y la cosmografía, podía haber acudido Sánchez para aprender las lecciones de álgebra que terminaría concertando con Antonio de Molina $^{18}$. Tal vez considerara que el nivel de dichos profesionales superaba sus inquietudes y necesidades y que sería suficiente con la instrucción de un maestro de "enseñar mozos a leer y escribir" para aprender "a contar todo el arte mayor así el aljebra como todo los demás al dicho arte tocante, como se contiene en el libro de Frater Lucar".

\section{APÉNDICE DOCUMENTAL}

Sevilla, 1550, marzo, 1. Conveniencia de Antón Molina con Juan Sánchez. Archivo Histórico Provincial de Sevilla, sección Protocolos Notariales, leg. 6710, oficio 11 (Francisco Romano), 1550, libro I, ff. 498v-499r.

"[F. $\left.1^{\mathrm{o}} \mathrm{v}\right]$ Sepan quantos esta carta vieren/ como yo Antón de Molina, maestro de/ enseñar mozos a leer y escribir, vecino que soi de esta/ çibdad de Sevilla en la collación de San Salvador, otorgo e/ conozco que soi convenido e concertado con vos Juan/ Sánchez, maestro mayor de la obra del cabildo/ de esta ciudad e vecino de ella en la collación de Santa/ María Magdalena que estades presente, en tal manera/ que yo sea obligado e me obligo de vos enseñar/ a contar toda el arte mayor así el aljebra como todo lo de-/ más al dicho arte tocante, como se contiene en el libro de Frater/ Lucar, con tanto que no sea obligado a vos enseñar la jeometría/ del dicho libro de Frater Lucar. Lo qual que dicho es, me obligo a vos/ enseñar de oy día de la fecha de esta carta en tres meses primeros/ siguientes sin faltar cosa alguna de ello, e por razón que/ vos lo muestre y enseñe me avéis de dar doze ducados de oro/ de los quales me avéis pagado e yo de vos he resçibido los ocho ducados de ellos, luego de contado de que soy e me otorgo por/ bien contento, pagado y entregado a mi voluntad sobre/ lo qual renuncio la eçebçión de la pecunia como en ella se contiene, e

${ }^{17}$ Al respecto véase PÉREZ-MALLAINA, Pablo E.: "La eclosión de la ciencia", en MARTÍNEZ SHAW, Carlos (dir.): Sevilla, siglo XVI. El corazón de las riquezas del mundo. Madrid, 1993, pp. 232-245. Del mismo autor "La Casa de la Contratación y la ciencia", Andalucía en la Historia, 2, 2003, pp. 28-33.

${ }^{18}$ Sobre el tema de las matemáticas y la cosmografía puede consultarse ESTEBAN PIÑERO, M.: "Cosmografía y matemáticas en la España de 1530 a 1630", Hispania: Revista Española de Historia, vol. 51, 177, 1991, pp. 377-397. 
los/ quatro ducados restantes me avéis de dar e pagar a-/ quí en Sevilla sin pleito alguno en fin de los dichos tres meses/ so pena del doblo, e si no vos diere enseñado de lo suso dicho/ en fin de los tres meses como dicho es, que en tal caso vos/ el dicho Juan Sánchez no me paguéis los dichos quatro ducados/ que asy me avéis de dar en fin de los dichos tres meses, e de/ más de esto yo sea obligado e me obligo a vos bolver quatro/ ducados de los dichos ocho ducados que de vos tengo reçibidos e en-/ tiendese como dicho es, que no os tengo de enseñar la dicha jeome-/ tría del dicho libro, sino todo lo demás en él contenidos, con condiçión/ que vos el dicho Juan Sánchez no seáis obligado a enseñar el/ dicho arte a persona alguna en ningún tiempo so la pena de esta/ carta e con condiçión que si antes de los dichos tres meses yo/ os mostrare y enseñare lo suso dicho, que antes seáis obligado/ a me pagar los dichos quatro ducados. Y en esta manera e/ segund dicho es, prometo e me obligo de fazer conplir lo suso/ e de no me quitar de ello por causa ni razón alguna, e vos/ el dicho Juan Sánchez que me non podades dexar so pena de/ cinco mil maravedís en la parte de nos ynobidiente que contra lo suso/ dicho fuere o vinyere, de e pague e peche a la otra parte de/ [f. $2^{\circ}$ r] nos obidiente que por ello estuviere e lo oviere por firme con más/ las costas que sobre ello se le recreçieren e la dicha pena pagada/ o no, que lo aquí contenido vala e sea firme e yo el dicho Juan Sánchez que a lo que/ dicho es presente soy, otorgo e conozco que acepto lo suso dicho segund e como/ por vos el dicho Antón de Molina está fecho e otorgado e me obligo de/ pagar e conplir los suso dicho al plazo e de la manera que en esta carta/ se contiene so las dichas penas e de más desto, si nos anbas las/ dichas partes así no lo pagaremos o cunplieremos por esta carta, cada/ uno de nos por lo que le toca, damos poder conplido a todos e/ qualesquier alcaldes, jueces e justiçias de sus majestades de qualesquier fuero/ e juridiçión que sean para que por todos los remedios y/ rigores del derecho e por vía executiva nos conpelan e apremien a lo/ así pagar e cumplir bien asy como si lo que dicho es, fuese sentencia dy-/ finitiva de juez conpetente, pasada en cosa juzgada, sobre/ lo qual renunciamos todas e quales quier leyes, fueros y derechos que en/ nuestro favor sean, e especialmente renunciamos la ley que dize que general/ renuçiaçión de leyes no vala e pa lo asy pagar e conplir/ e aver por firme, obligamos cada una de nos las dichas/ partes porque lo que le toca su persona y bienes avidos e/ por aver, fecha la carta en Sevilla, estando en el Oficio del escribano público yuso escripto, sábado, primero día del mes de março./ Año del nasçimyento del nuestro salvador Jesucristo de/ mil e quinientos e çinquenta años, e los dichos otorgantes/ lo firmaron de sus nombres en este registro, testigos/ que fueron presentes a lo que dicho es: Juan Gutiérrez e Juan de Al-/ cántara, escribanos de Sevilla.

Convenençia de le enseñar el arte mayor de contar/

Firman de izquierda a derecha:

Juan de Alcántara (escribano de Sevilla), Juan Sánchez, Antón de Molina y Juan Gutiérrez (escribano de Sevilla)."

Fecha de recepción: 30 de octubre de 2018

Fecha de aceptación: 5 de febrero de 2019 